
ciertos requisitos con los que deben cumplir cada una de ellas. Este es un estudio preliminar, y con análisis de fallos, de la legitimación procesal o en el proceso.

A la Corte Suprema de Justicia le compete el control de la legalidad de las resoluciones de los juzgadores de instancia. Este control lo ejerce a través de sus fallos, dictados como Tribunal de Casación.

En reiterados fallos de la Primera Sala de lo Civil y Mercantil podemos ver que los Magistrados se han visto en la necesidad de precisar dos conceptos de uso muy frecuente en el debate procesal: el de la ilegitimidad de personería y el de falta de derecho del actor o ilegítimo contradictor. Es que los tribunales y jueces inferiores tienden, en muchos casos, a considerarlos como sinónimos. ${ }^{1}$

Estos conceptos tienen vinculación directa con la intervención de las partes en el proceso civil, por lo que, para comprenderlos en su correcto alcance, haremos un breve recorrido a través de los requisitos con los que deben cumplir las personas que intervienen en un proceso y cuya falta u omisión puede influir en la validez del proceso o en la eficacia del resultado procesal.

\section{La Ilegrtimidad de Personería}

Según el artículo 355 del Código de Procedimiento Civil, la legitimidad de personería es una solemnidad sustancial común a todos los juicios e instancias. En nuestro ordenamiento jurídico no se la define, sin embargo la ley establece que la falta de legitimación de personería (ilegitimidad de personería) se produce por:

a) incapacidad legal; o

b) falta de poder, que será motivo de una excepción dilatoria (artículo 104 del Código de Procedimiento Civil).

\section{LA FALTA DE DERECHO DEL ACTOR (ACTIVA) O ILE- GÍTIMO CONTRADICTOR (PASIVA)}

Respecto de la falta de derecho del actor o ilegítimo contradictor, el Código de Procedimiento Civil no contempla una norma específica destinada al tema, no se la señala como excepción, ni dilatoria (artículo 104 CPC), ni perentoria (105 CPC) y tampoco como presupuesto o solemnidad sustancial para la validez del proceso (artículo 355 CPC).

Sin embargo, en varias normas, y en especial en aquellas relativas a juicios especiales, encontramos referencia al derecho del actor para ejercer la acción o presentar la demanda correspondiente, y contra quién debe dirigirse esa demanda en calidad de demandado.

Así por ejemplo, en el Código de Procedimiento Civil en la Sección 14a. Del Juicio de Alimentos, el artículo 735 dice: "Propuesta la demanda de alimentos, el juez concederá el término de cuatro días, para que se acrediten el derecho del demandante y la cuantía de los bienes del demandado..", y el artículo 739 ibídem: "En los juicios sobre alimentos legales, si la parte actora fuere la madre de un menor de edad o de un demente que se halle bajo su cuidado, podrá comparecer en juicio, por sí misma, cualquiera que sea su edad, para demandar dichos alimentos para su hijo, al padre de éste o a cualquiera otra persona que tenga obligación de suministrarlos".

En un proceso contencioso, generalmente la persona que comparece físicamente al proceso es aquella a la que se atribuye los efectos jurídicos del proceso. Pero es frecuente también que la persona que comparece físicamente al proceso no es aquella a quien se atribuye los efectos jurídicos del proceso. Un ejemplo: el procurador judicial comparece a juicio y es él quien comparece físicamente al proceso y realiza los actos procesales; pero los efectos jurídicos del proceso se atribuyen al mandante que otorgó la procuración judicial. Por esto, en nuestro análisis haremos la distinción entre: 1.- la persona a quien se atribuyen los efectos jurídicos del proceso; y 2.- la persona que comparece físicamente al proceso y realiza los actos procesales. Ahora bien, para que la intervención de estas personas sea eficaz y surta los efectos jurídicos deseados por ellas, deben cumplir con ciertos requisitos: la persona a quien se atribuyen los efectos jurídicos debe tener capacidad para ser sujeto de derechos y legitimación en la causa; mientras que la persona que comparece físicamente al 
proceso y realiza los actos procesales debe tener capacidad procesal y legitimación procesal.

\section{De la Persona a la QUe Se atribuYe los EFECTOS JURIDICOS DEL PROCESO}

Empezaremos por analizar los requisitos de quien, pese a no comparecer físicamente o directamente al proceso, es la persona a la que se atribuye los efectos jurídicos del proceso: es decir quien se beneficia o perjudica con el resultado procesal. Estos requisitos son la capacidad para ser sujeto de derechos y la legitimación en la causa.

\section{a. Capacidad para ser sujeto de derechos}

La capacidad para ser sujeto de derechos existe cuando se presentan ciertas circunstancias intrínsecas a la persona. Estas circunstancias son el hecho del nacimiento, cuando la persona es natural, según el artículo 60 del Código Civil que establece "El nacimiento de una persona fija el principio de su existencia legal, desde que es separada completamente de su madre"; y el reconocimiento, otorgándole personería, cuando la persona es jurídica.

El autor ecuatoriano Alfonso Troya Cevallos opina: "La capacidad de comparecer en juicio tienen (sic) todas las personas naturales y jurídicas por el hecho de existir" (Troya Cevallos: 297). Se podría vincular las circunstancias requeridas para ser sujeto de derechos con las requeridas para ser parte procesal, y así estar vinculada por los efectos jurídicos del proceso. Sin embargo, pueden concurrir como partes ciertos patrimonios, a pesar de no tener la condición de sujetos de derechos: la herencia yacente o la masa de bienes de la quiebra o concurso.

Pero, ¿qué sucede si falta esta capacidad? Por ejemplo, si comparece en juicio una persona en representación de una persona fallecida, o en representación de una persona jurídica que no tiene personería jurídica.

La capacidad de quien se beneficia o perjudica de los efectos jurídicos de un proceso es un presupuesto indispensable para su validez, por lo que su ausencia es causa de nulidad insubsanable. Igual sucede respecto de la ausencia de dicha capacidad en la persona contra quien se inicia un proceso, por ejemplo si se demanda a una persona fallecida o que nunca existió.

Sin embargo, obsérvese que la ley establece la presunción de existencia de esta capacidad pero, por tratarse de una presunción simple, admite prueba en contrario.

La resolución del juez que rechaza la demanda por ausencia de esta capacidad tendrá el carácter de interlocutoria o inhibitoria, la misma que no produce efectos de cosa juzgada. ${ }^{2}$

En cuanto a las alternativas que tiene la contraparte para oponerse en un proceso que padece de un defecto por falta de capacidad, tenemos las siguientes:

a. la oposición de excepción de ilegitimidad de personería;

b. la reclamación de existencia de ilegitimidad de personería a través de los recursos;

c. la presentación de incidentes;

d. la acción de nulidad de sentencia (artículo 303, numeral 2)

La doctrina moderna establece que la ilegitimidad de personería se produce únicamente cuando falta el vínculo que justifique la legítima intervención de un representan- te legal o de un procurador. Sin embargo, en nuestro ordenamiento legal y en virtud de la norma recogida en el artículo 104 del Código de Procedimiento Civil, la ilegitimidad de personería se produce, no sólo por falta de poder, sino también cuando quien comparece lo hace sin capacidad legal.

Esta es, entonces, una primera aproximación al concepto de ilegitimidad de personería.

\section{b. Legitimación en la causa}

La legitimación en la causa, al contrario de la capacidad, no es parte de la naturaleza íntima de la persona a quien se atribuye los efectos jurídicos del proceso. Es más bien un requisito extrínseco a ella y consiste en la necesidad de que entre esta persona y el objeto del proceso concreto exista algún vínculo que "legitime" la intervención de tal sujeto, permitiendo que la sentencia dictada dentro de un proceso surta plenos efectos.

Esta vinculación que deben tener las partes con el objeto del proceso (o con la relación jurídica sustantiva que sobre éste recae) habilita a una de ellas para asumir la posición de actor y coloca a la otra en la necesidad de soportar la carga de ser demandado. ${ }^{3}$

El autor ecuatoriano Cruz afirma que son las leyes sustantivas y adjetivas las que exigen que en el proceso comparezca a contradecir la parte que reúna ciertas características y represente los derechos que invoca. Cita como ejemplo el siguiente: "es legítimo contradictor en la acción o en la excepción, cuando de los asuntos de una sucesión indivisa se trate, todo herederos de la persona difunta, sin cuya presencia mo puede discutírselos válidamente". (Cruz Bahamonde : 130) El caso expuesto por Cruz es un típico caso de litisconsorcio necesario, en el que se requiere necesariamente la comparecencia de varias personas, sea como actores o como demandados. ${ }^{4}$

La falta de legitimación en la causa puede afectar tanto al actor como al demandado: en el primer caso es activa y en el segundo, pasiva.

Pero, ¿qué sucede si falta la legitimación en la causa? La legitimación en la causa no es presupuesto de la validez del proceso, sin embargo lo es de la sentencia de fondo o de mérito, por lo que su falta impide al juzgador pronunciar sentencia de fondo. La resolución del juez que rechaza la demanda por falta de legitimación en la causa tendrá el carácter de interlocutoria o inhibitoria, por lo tanto no produce efectos de cosa juzgada, lo cual permite que, una vez subsanado el defecto, pueda plantearse la acción nuevamente. ${ }^{5}$ En cuanto a las alternativas que tiene la contraparte para oponerse a un proceso en que existe falta de legitimación en la causa éstas son:

a. excepción de falta de derecho del actor (activa) o excepción de ilegítimo contradictor (pasiva)

b. opciones a través de los recursos

Obsérvese que la falta de legitimación en la causa no es presupuesto de la acción de nulidad de sentencia.

\section{DE LA PERSONA QUE COMPARECE DIRECTA- MENTE AL PROCESO Y REALIZA LOS ACTOS PROCESALES}

La persona que comparece directamente al proceso, puede al mismo tiempo ser a la que se atribuya los efec- 
tos jurídicos del proceso. Pero puede suceder también que sean personas diferentes: una, la que físicamente comparece al proceso y otra, la que se atribuya los efectos jurídicos.

El sujeto que físicamente comparece al proceso debe reunir dos requisitos: capacidad procesal y legitimación procesal.

\section{a. La capacidad procesal}

Consiste en la aptitud que debe tener la persona que comparece al proceso por sí mismo y que existe cuando se presentan ciertas circunstancias intrínsecas al mismo. Esas circunstancias son haber cumplido 18 años, cuando es persona natural, y tener representante legal cuando es persona jurídica. Pese a que todas las personas -por el hecho de su existencia- tienen capacidad jurídica no todas pueden intervenir personal, directa e independientemente en un proceso.

Esta capacidad procesal para comparecer en un proceso por sí mismo se suele denominar en la doctrina legitimatio ad processum, término que mira a la capacidad jurídica, a la capacidad procesal y a la debida representación. A esta última nos referiremos en el siguiente punto.

"La capacidad de comparecer en juicio la tienen todas las personas naturales jurídicas por el hecho de existir; pero no pueden ejercer por sí mismas ese derecho aquellas que la ley las ha declarado incapaces (...) distínguese la capacidad de goce de la capacidad de ejercicio, por la primera la persona es apta para adquirir derechos, lo cual es propia de todas (...), por las segundas podemos ejercer los derechos que nos pertenecen por nosotros mismos, sin necesidad de representación ni de autorización de otra persona" (Troya: 297).

El artículo 34 del Código de Procedimiento Civil señala los casos de quienes no pueden comparecer por sí mismos a juicio como actores ni como demandados: 1.- el menor de edad; 2 .- quienes se hallen bajo tutela o curaduría; y 3.- las personas jurídicas.

Por regla general, carecen de capacidad de ejercicio los menores de edad y las personas jurídicas; sin embargo, hay otras incapacidades que se establecen en virtud de otras razones que no son la minoría de edad o la falta de representación legal; como la demencia o la sordomudez, cuando el sordomudo no puede darse a entender por escrito; el alcohólico, el disipador, el drogadicto.

Todas las personas, pese a carecer de capacidad procesal, pueden ser partes en un proceso; sin embargo, no pueden hacerlo por sí mismos.

¿Qué sucede si quien comparece carece de capacidad procesal ?

Así, por ejemplo, si demanda un menor de edad, o quien se encuentra en estado de interdicción declarada por el juez. La capacidad procesal de quien comparece directamente a un proceso es un presupuesto indispensable para la validez del mismo, por lo que su ausencia es causa de nulidad, pero a diferencia de la capacidad para ser sujeto de derechos, esta capacidad es perfectamente subsanable mediante la posterior ratificación del representa$\mathrm{do}^{6}$. Sin embargo, el no hacerlo acarrearía la nulidad del proceso.

En cuanto a las alternativas que tiene la contraparte para oponerse en un proceso que padece de un defecto por falta de capacidad procesal de quien comparece físicamente al proceso, éstas son las siguientes:

\section{Dentro del Proceso:}

a. la oposición de la excepción de ilegitimidad de personería : "En el derecho procesal la incapacidad (de ejercicio) de cualquier grado que sea trae consigo la imposibilidad legal de comparecer en juicio; la comparecencia de un incapaz ocasiona la falta de personería y en consecuencia la nulidad procesal. La capacidad procesal es, pues, la idea paralela a la que en campo meramente civil tenemos del pleno ejercicio de los derechos civiles" (Troya: 298). Cabe destacar que el artículo 109 del Código de Procedimiento Civil, señala que la ilegitimidad de personería procede por incapacidad legal, el uso de este concepto "incapacidad legal", creemos que debe entenderse como "la aptitud legal para adquirir derechos y ejercitarlos", por ello, si falta la capacidad procesal, cabe la excepción de ilegitimidad de personería.

b. mediante un incidente

Terminado el proceso:

c. a través de la acción de nulidad de sentencia, según el artículo 303, inciso segundo.

\section{b. Legitimación procesal}

Este requisito es indispensable para quien interviene directamente en el proceso en representación de otra persona, que es a quien se atribuyen los efectos jurídicos del proceso. Existe desde que se presenta un vínculo entre la persona que interviene directamente en el proceso y realiza los actos procesales y la persona a quien se atribuyen los efectos jurídicos del proceso. Este vínculo se denomina "representación".

La representación es una figura jurídica por la cual, como decían los romanos "absentis alicujons presens imago", se tiene presente la imagen de la persona ausente.

Por ello, la intervención del representante de la parte debe ser rodeada de los requisitos formales establecidos por la ley y contener, sine qua non, la expresión de su designación y la descripción de sus facultades para que ejerza la representación en el proceso. Esto se traduce en una operación procesal especial que constituye el vínculo y que se denomina legitimación de personería o legitimatio ad processum.

Por regla general, la representación opera respecto de las personas incapaces. Así, el artículo 34 del Código de Procedimiento Civil señala quiénes no pueden comparecer personalmente a juicio como actores ni como demandados (el menor de edad, quienes se encuentran bajo tutela o curaduría y las personas jurídicas). Sin embargo, este mismo artículo establece que pueden comparecer a juicio por medio de una tercera persona, el representante legal, que comparece físicamente al proceso y realiza los actos procesales, pero cuyos efectos no le son atribuibles sino al representado.

En efecto, como lo dice Cruz Bahamonde, los problemas que en proceso se presentan por la incapacidad de las personas que intervienen en los juicios, se resuelven mediante la institución de la representación (Cruz Bahamonde: 157).

Sin embargo, no sólo los incapaces pueden comparecer a juicio a través de una tercera persona: en efecto, la "representación" es una figura que opera también en otros casos. Este vínculo puede nacer de la ley, del discernimiento del juez o de la voluntad de las partes. 
Veamos cuáles son algunas formas de representación:

1. Los menores de edad.- Son representantes legales de los menores de edad conjuntamente el padre y la madre que ejerzan la patria potestad. Esta representación nace de la ley y se prueba acreditando la paternidad o maternidad del menor de edad, y opera tanto si el menor es actor como si es demandado (Art. $28 \mathrm{CC}$ ).

A falta de ambos padres, la representación de los menores corresponderá al tutor o curador que le haya sido designado. Si tampoco existe, el juez deberá designarle un curador ad litem, tanto si es actor como demandado.

Existen casos expresamente señalados en la ley en lo cuales, pese a la incapacidad de los menores, pueden comparecer por sí mismos al proceso, sin necesidad de un representante legal.

2. Los que han sido declarados interdictos. Es representante legal de estas personas para intervenir en un proceso el curador ad litem, designado por el juez.

3. El ausente o la persona cuyo paradero se ignora. Son representantes legales de estas personas para intervenir en el proceso, el curador ad litem, designado por el juez.

4. Las personas jurídicas. Son representantes legales de las personas jurídicas aquellas designadas en el contrato o estatuto que las rige. Art. $589 \mathrm{CC}$.

6. El Estado.- Es representante legal del Estado y demás entidades públicas que carecen de personería jurídica, el Procurador General del Estado.

7. La persona que tiene capacidad procesal, pero que no quiere o no puede comparecer directamente a un proceso, puede mediante un acto unilateral designar un procurador judicial. La procuración judicial es un acto voluntario. Según el artículo 44 del Código de Procedimiento Civil en concordancia con el artículo 49 de la Ley de Federación de Abogados, disponen que la procuración judicial sólo podrá otorgarse a quien ostente la calidad profesional de abogado. Estas mismas disposiciones establecen que la procuración judicial se otorgue mediante escritura pública.

8. La agencia oficiosa. Conforme al artículo 371 del Código de Procedimiento Civil, cualquier persona, sin necesidad de poder, puede promover demanda a nombre de otra persona que esté ausente o impedida de hacerlo, con el fin de evitar que sufra algún perjuicio. Sin embargo, la condición para que esta comparecencia sea válida es que legitime su personería o presente la aprobación de aquel por quien gestiono.?

9. Pluralidad de actores o demandados. El artículo 56 del Código de Procedimiento Civil ha previsto que ante la concurrencia plural de personas en la parte actora con un mismo derecho, o en la parte demandada, cuyos derechos de excepción no sean diversos ni contrapuestos, el juez por economía procesal dispone que uno de los actores o los demandados sirva de procurador, para contar con él en el juicio. ${ }^{10}$

En todos los casos de representación, sea que el vínculo nace de la ley, del discemimiento del juez o de la voluntad de las partes, el efecto principal es que las consecuencias jurídicas del proceso recaen sobre el repre- sentado y no sobre el representante: "el representante es el que realiza el acto jurídico y, por lo mismo es de su persona de quien emana el acto de voluntad; que los efectos jurídicos del acto se producen con respecto al representado; los actos del representante son como si fueran realizados por el representado y obligan a éste en toda forma de derecho, efecto que se produce siempre que el representante actúe dentro de los términos de su encargo" (Cruz Bahamonde: 159).

En todos los casos en que no existe o no se acredite el vínculo en virtud del cual el representante actúa en representación del representado, estamos ante una indebida representación y por lo tanto en un caso de ilegitimidad de personería o falta de legitimatio ad processum. Pero también, en aquellos casos en que existe el vínculo, pero éste no ha sido otorgado conforme a la ley (es decir existe un defecto en dicho vínculo) la representación no surte efectos y por lo tanto también procede la excepción de ilegitimidad de personería o falta de legitimatio ad proces sum. "La capacidad procesal de quien comparece directamente a un proceso es un presupuesto indispensable para la validez del mismo, por lo que su ausencia originaría su nulidad. Pero, a diferencia de la capacidad para ser sujeto de derecho, esta capacidad es perfectamente subsanable mediante la posterior ratificación del representado. Sin embargo, el no hacerlo acarrea la nulidad del proceso.

La legitimación procesal de quien comparece en representación de un tercero es un presupuesto indispensable para de la validez del proceso, por lo que su omisión es causa de nulidad. Pero al igual que la capacidad procesal, subsanable, pero si el representante legal o el procurador no legitiman su intervención en el proceso, pueden incurrir en la causal 3 del artículo 355 del Código de Procedimiento Civil. "Si se trata de falta de personería, la excepción es meramente dilatoria y su resolución se daría mediante una providencia interlocutoria" (p. 321 Troya).

La intervención de las personas en un proceso está, como hemos visto, sometida a ciertos requisitos con los que deben cumplir cada una de ellas, requisitos que se ubican, cada uno de ellos, en un área específica del derecho. Lo que hemos querido hacer en esta breve introducción, es empezar a trazar un camino en el estudio de la le. gitimatio ad processum (legitimación procesal o en el proceso) y de la legitimatio ad caussam (legitimación en la causa) - que si bien no son conceptos nuevos, pues cada uno corresponde a lo que conocemos como ilegitimidad de personería y falta de derecho del actor cuando es activa e ilegítimo contradictor cuando es pasiva- la doctrina moderna los ha desarrollado desde nuevas perspectivas. Hay que relievar el trabajo que a este respecto está llevando a cabo la Corte Suprema de Justicia, pues en sus fallos se denota cada vez más claridad conceptual, lo cual colabora al desarrollo del Derecho.

Este trabajo de ninguna manera pretende agotar el tema: cada uno de los temas tratados merece especial estudio. Nos referimos en especial a la legitimatio ad caussam, que sin duda es un tema de gran trascendencia. 
1. Ha dicho la Corte Suprema: "Por lo tanto, la conclusión a la que llegan los Ministros de la Segunda Sala de la Corte Superior de Loja de que existe ilegitimidad de personería por cuanto la accionante no ha comparecido con su cónyuge, carece de fundamento legal, ya que ella está actuando por sus propios derechos y no en representación de su marido o de la sociedad conyugal.- El Tribunal de instancia ha confundido lamentablemente lo que es la ilegitimidad de personería con lo que es la falta de legítimo contradictor o falta de legitimación en la causa (legitimatio ad causam)", de la Resolución de la Primera Sala de lo Civil y Mercantil N ${ }^{\circ} 372-99$, dictada dentro del juicio $N^{\circ} 820-94$ y publicada en el Registro Oficial $N^{\circ} 257$ de 18 de agosto de 1999.

"La demandada al proponer la excepción de falta de personería dice que lo hace por no haberse demandado a su cónyuge en razón de que el inmueble (objeto de este controvertido) pertenece a la sociedad conyugal. Como quedó indicado, en nuestro país no se han desarrollado los conceptos de falta de legitimación ad processum y de falta de legitimación ad caussam; y es muy común que al amparo de la excepción 'falta de personería', se introduzcan indistintamente una u otra de las excepciones indicadas; este error aparece en la especie nítidamente cuando la accionada en su contestación a la demanda plantea la acción de falta de personería pero se refiere a la necesidad de vincular a su marido a la parte demandada por tratarse de una reclamación que afecta un bien social", de la Resolución de la Primera Sala de lo Civil y Mercantil $N^{\circ} 405-99$, dictada dentro del juicio 31-96, publicada en el Registro Oficial No. 273 de 9 de septiembre de 1999.

2. Al respecto, la Corte Suprema ha sostenido lo siguiente: "La sentencia, por lo general decide el fondo o mérito del asunto $o$ asuntos de la controversia; pero hay casos en que al juez no le es posible dictar sentencia de mérito o fondo, porque el proceso está viciado de nulidad insanable por omisión de los presupuestos procesales de la acción, o porque se han omitido presupuestos de la demanda... entonces dicta sentencia inhibitoria que es aquella en que el juez se abstiene de decidir sobre el mérito del conflicto planteado. Ordinariamente, la sentencia de mérito o de fondo definitiva produce autoridad de cosa juzgada material, como acto jurídico decisorio definitivo, la sentencia tiene efectos obligatorios tanto frente al órgano jurisdiccional que lo ha dictado, el cual no puede revocarla, como frente a todos los demás órganos jurisdiccionales que están prohibidos de conocer y resolver el mismo asunto; la sentencia tiene también efecto obligatorio frente a las partes, que no pueden ya acudir ante un órgano jurisdiccional, cualquiera que sea su competencia, para obtener una nueva sentencia. La sentencia inhibitoria, en cambio, es meramente formal y si bien pone fin al juicio en que se dicta, deja a salvo el derecho del interesado de replantear la cuestión en otro proceso posterior, porque como no hay en ella decisión de fondo, ni positiva ni negativa, no produce autoridad de cosa juzgada", de la Resolución de la Primera Sala de lo Civil y Mercantil $N^{\circ} 146-2000$ dictada dentro del juicio $\mathrm{N}^{\circ}$ 100-99 aun no publicada en el Registro Oficial a la fecha de la publicación de este artículo.

3. Sobre la legitimación en la causa o legitimatio ad caussam, se ha dicho: "es preciso distinguir lo que es la ilegitimidad de personería de lo que es la falta de legítimo contradictor, o falta de legitimación en la causa (legitimatio ad causam), que consiste en que el actor debe ser la persona que pretende ser el titular del derecho sustancial discutido, y el demandado el llamado por la ley a contradecir u oponerse a la demanda, pues es frente a ellos que la ley permite que el juez declare, en sentencia de mérito, si existe o no la relación jurídica sustancial objeto de la demanda, sentencia que los obliga y produce cosa juzgada sustancial", de la Resolución de la Primera Sala de lo Civil y Mercantil $N^{\circ}$ 516-99 dictada dentro del juicio $\mathrm{N}^{\circ} 159-98$.

4. "Por otra parte, la legitimación en la causa o legitimatio ad causam "Determina no sólo quienes deben obrar en el proceso con derecho a obtener sentencia de fondo, sino, además, quienes deben estar presentes para que sea posible esa decisión de fondo. Se habla de necesarios contradictores, para indicar que en ciertos procesos es indispensable que concurran determinadas personas (como litisconsortes necesarios), bien sea como demandantes o como demandados, para que la decisión sobre las peticiones de la demanda sea posible", de la Resolución de la Primera Sala de lo Civil y Mercantil No 372-99 dictada dentro del juicio $N^{\circ} 820-94$ y que recoge el criterio del autor colombiano Hernando Devis Echandía; esta resolución está publicada en el Registro Oficial № 257 de 18 de Agosto de 1999. 


\section{NOTAS}

"Cuando en un contrato una de las partes está integrada por varias personas, la relación sujeto y objeto debe establecerse entre cada una de ellas y el objeto que viene a ser la relación sustancial, la no concurrencia de una persona acarrea la falta de legitimación ad caussam; y es que hay casos en que la presencia en el proceso de todos los sujetos vinculados a un contrato (relación sustancial) se hace indispensable a fin de que la relación jurídica procesal quede completa y sea posible decidir sobre el fondo de ella; si los sujetos son dos o más, pero forman un solo sujeto, estamos en presencia de un litis consorcio necesario y su comparencia es indispensable", de la Resolución de la Primera Sala de lo Civil y Mercantil N 118-99 dictada dentro del juicio 100-96 y publicada en el Registro Oficial $N^{\circ} 160$ del 31 de marzo de 1999.

5. Sobre el tema, ha dicho la Corte Suprema: "de otra parte, la sentencia dictada en el primer proceso únicamente produjo efecto de cosa juzgada formal pero no sustancial porque la demanda que propuso $\mathrm{MCQ}$ era inepta para prosperar, y así efectivamente ocurrió porque, siendo un caso de litis consorcio necesario, ella debía accionar conjuntamente con MEQ por las dos las únicas y universales herederas de sus padres... es decir, no hubo la completa integración del litis consorcio y al no haber existido en la parte actora la legitimatio ad caussam', la sentencia dictada se limitó a rechazar la acción por no proceder en la forma propuesta, sin entrar a resolver sobre el objeto del controvertido, por lo que tuvo el carácter de inhibitoria, que no impide el que se vuelva a plantear la acción una vez que se haya integrado adecuadamente el litis consorcio necesario, como ocurren en la presente causa", de la Resolución de la Primera Sala de lo Civil y Mercantil $N^{\circ} 187-99$, dictada dentro del juicio $N^{\circ} 33-94$, publicada en el Registro Oficial $N^{\circ} 208$ de 09 de junio de 1999.

6. "Cuando existe ilegitimidad de personería, generalmente cabe ratificación de la parte, con lo cual se convalidan los actos realizados por la persona que carecía de capacidad para comparecer a juicio (Arts. 368 a $371 \mathrm{CPC}$ ), de la Resolución de la Primera Sala de lo Civil y Mercantil No $372-99$, dictada dentro del juicio $N^{\circ} 820$ 94 y publicada en el Registro Oficial N 257 de 18 de agosto de 1999".

7. "El escrito de sustitución de poder, en mérito del cual deduce el recurso de casación el doctor EB, no está reconocido ante el juez de la causa... Por esta razón no cumple con el requisito de forma exigido por el inciso segundo de la Ley de Federación de Abogados y, consiguientemente, no tiene validez. Siendo así, el doctor EB no ostentaba legitimación activa, legitimatio ad processum, para interponer el recurso de casación como manda el artículo 4 de la Ley de la materia", de la Resolución $\mathbf{N}^{\circ}$ $170-99$, dictada dentro del juicio $N^{\circ} 757-95$ y publicada en el Registro Oficial $N^{\circ}$ 208 de 09 de junio de 1999.

8. "La representación extrajudicial del Estado la ejerce el Presidente de la República, sin embargo, la representación judicial, y por mandato judicial (....actual artículo 216) la ejerce exclusivamente el Procurador General del Estado. La Ley Orgánica del Ministerio Público, también vigente a la fecha de presentación de la demanda, en su artículo 11 literal a), establece que al Procurador General le corresponde representar judicialmente al Estado. Los Ministerios de Estado son órganos integrantes de la Función Ejecutiva, carecen de personalidad jurídica única, distinta de la personalidad de la Administración Pública Central y por ello, no están comprendidos, como erróneamente afirma el recurrente, dentro de las instituciones del Estado, regidas por leyes especiales que serán representadas en juicio por sus representantes legales y en cuyos casos el Procurador general interviene para vigilar las actuaciones procesales sin que su intervención sea obligatoria", de la Resolución de la Primera Sala de lo Civil y Mercantil No 181-2000, dictada dentro del juicio 26199 y aún no publicada en el Registro Oficial.

"En el presente caso las partes procesales son: a) como actor el Instituto Técnico Superior IPP, institución fiscal, que forma parte de las entidades del gobierno central, y que carece de personería jurídica, por lo tanto para comparecer a juicio debe ser representada por el señor Procurador General del Estado o su delegado... según lo disponen los artículos 216 de la Constitución Política de la República y 3 de la Ley Orgánica de la Procuraduría General del Estado. Por lo tanto y en el caso que nos ocupa, los únicos legitimados para interponer válidamente el recurso de casación eran el Procurador General del Estado o su delegado y de ninguna manera la rectora del Instituto Técnico Superior.,., pues dicha institución carece de personalidad jurídica propia, sino que es parte integrante de la Administración Pública Cen- 
NotAS

tral por ser parte del Ministerio de Educación y Cultura, ya que la representación oficial del establecimiento que le confiere el artículo 95 del Reglamento a la Ley de Educación no implica de modo alguno la representación judicial respecto de la cual las disposiciones normativas de carácter jerárquicamente superior que han sido señaladas le asignan al señor Procurador General del Estado, dicha representación"; de la resolución $\mathrm{N}^{\circ}$ 204-2000 dictada dentro del juicio $\mathrm{N}^{\circ} 110-2000$, aun no publicada en el Registro Oficial. Igual criterio sostuvo esa Sala en Resolución $N^{\circ} 177$ 2000 , dictada dentro del juicio $N^{\circ}$ 92-2000, aun no publicada en el Registro Oficial.

9. Este criterio ha mantenido la Primera Sala de lo Civil y Mercantil en su fallo dictado dentro del juicio $\mathrm{N}^{\circ} 604-95$ y publicado en el Registro Oficial $\mathrm{N}^{\circ} 39$ de 2 de octubre de 1998.

10. A criterio de la Primera Sala de la Corte Suprema de Justicia, éste es un caso de "verdadera representación legal de cumplimiento obligatorio e inexcusable y que priva a los demás del derecho a intervenir o a ser tomados en cuenta... Cierto es que el procurador común se lo designa dentro del juicio; para el efecto, el juez concede un término, a fin de que los litis consortes, señalen la persona que se desempeñará como procurador común, y si no lo hicieren, será el propio juez el que designe a la persona que debe servir de procurador y con él se contará en juicio; y cuando fallece uno de los litis consortes. es necesario proceder a una nueva designación de procurador común", de la Resolución N॰459-99, dictada dentro del juicio 166-99 y publicada en el Registro Oficial N 332 de 03 de diciembre de 1999.

11. Al respecto, la Corte ha dicho: "la recurrente al no ser abogada no puede ejercer la procuración judicial de ninguna de las partes en un proceso, por lo que en la especie no estaba legitimada para interponer ni el recurso de casación ni el de hecho, y el tribunal que ha procedido conforme a derecho al negar la concesión del recurso de casación", de la Resolución de la Primera Sala de lo Civil y Mercantil N 459 99 , dictada dentro del juicio $N^{\circ} 166-99$ y publicada en el Registro Oficial $N^{\circ} 332$ de 03 de diciembre de 1999. 